\title{
Recognising and supporting self in dementia: a new way to facilitate a person-centred approach to dementia care
}

\author{
FIONA KELLY*
}

\begin{abstract}
This paper reports findings from a three-year study which integrated Kitwood's (1997) person-centred and Sabat's (200I) selfhood approaches in the design, fieldwork and analysis of a multi-method observational study that explored the social worlds of I4 people with dementia in continuing-care. The types of interactions that participants experienced in everyday ward life and during creative sessions were identified by observing, video-recording and engaging with them and by Dementia Care Mapping. The participants' responses to such interactions in terms of their well- or ill-being and expressions of self were identified and documented. The findings indicate that in the wards, staff interactions were often limited and sometimes abusive and that participants experienced ill-being, whereas during creative sessions, interactions were generally facilitatory and celebratory with the participants experiencing wellbeing. By developing the selfhood approach and integrating it with the person-centred approach, I argue that recognising and supporting selfhood (or not) during interactions can lead to qualitatively different staff behaviours, with consequences for the well- or ill-being of people with dementia. There is scope for incorporating this developed selfhood framework into staff training, for it has the potential to transform practice and the experiences of people with dementia in receipt of care.
\end{abstract}

$\boldsymbol{K E Y} \boldsymbol{W} \boldsymbol{W} \boldsymbol{D} \boldsymbol{S}$ - dementia, person-centred/selfhood approach, well/ill-being, long-term care.

\section{Introduction}

It is fundamental to successful interaction between people that each party is 'present' with and for the other (Kitwood 1997: irg), letting go of the drive 'to do' and focusing more on 'being' with people in creative, flexible, compassionate and responsive ways. This principle should equally extend to the support and care of people with dementia, and has been promoted through the use of a person-centred approach within dementia

* Dementia Services Development Centre, University of Stirling, Stirling, UK. 
care. Despite the rhetoric that encourages a person-centred approach, there is evidence that services in the United Kingdom for people with dementia continue to be at times inadequate, and that they are uncoordinated and inconsistent from region to region (National Audit Office 2007; Sutherland 2008). As the global economic impact of dementia is projected to increase (Knapp et al. 2007; Knapp and Prince 2007), there will be increasing pressures on health and social care services to meet the needs of people with dementia more effectively, particularly when severe cognitive decline and frailty demand more intensive services. With people entering continuing-care at a later age, care-home staff are now responsible for more highly dependent people with advanced dementia (National Audit Office 2007). This has implications for staffing levels, types of training, resources, workload and quality of care. With the many demands on their time and resources constraints, how can care staff fully attend to and be present for the increasing numbers of people with dementia in their care? Crucially, how can we successfully promote person-centred practice?

This paper aims to address these concerns by reference to a multimethod empirical study in three continuing-care wards of a psychogeriatric hospital. The study examined the types of interaction that I4 people with dementia experienced in everyday ward life and during creative sessions (painting and collage work) facilitated by occupational therapy (OT) staff. The study asked three key questions:

I. What types of interaction occur in wards and creative sessions?

2. How do participants with dementia express self in wards and during creative sessions and what factors influence self-expression?

3. What is the relationship between interaction types, wellbeing and selfexpression?

An understanding of differences in interaction types, and the possible reasons for these, is not only important for practice development, but also for extending the theoretical understanding of dementia care. Two of these theoretical understandings, the person-centred and selfhood approaches, will be discussed in order to contextualise the study and its findings.

\section{Theoretical background}

The person-centred approach

A person-centred approach to dementia care has at its core the goal of maintaining the personhood of people with dementia. The concept of 
personhood is a relatively new consideration in the care of people with dementia; it emerged through the work of Kitwood and Bredin (1992), who challenged the dominant biomedical paradigm that conceptualises dementia in terms of neurodegenerative pathology, decline and loss. In that paradigm, people labelled with the term 'dementia' were in danger of being transformed from a spouse, parent or friend to a 'wanderer' or 'demented', resulting in a significant undermining of their personhoods. Kitwood's (1997: 8) often cited and critiqued (Judd 2007; Kelly 2007) definition of personhood is, 'a standing or status that is bestowed upon one human being, by others, in the context of relationship and social being. It implies recognition, respect and trust'.

Kitwood (1997: 45) charged the dominant medical paradigm with contributing to care practices that involved 'bestialization, the attribution of moral deficit, warehousing and the unnecessary use of a medical model'. $\mathrm{He}$ argued that people with dementia who endure this type of care are at risk of depersonalisation because their personhoods are consistently undermined, and suggested that depersonalisation can occur through a dialectical interplay between neurological alterations in brain function and exposure to a negative social environment, which results in an unintended iterative negative spiral that leads to catastrophic psychological damage to people with dementia. Kitwood identified I7 elements of negative interaction which, in order to highlight their pervasiveness in society and potential for psychological damage, he termed 'malignant social psychology' (1997: 46-7). They include treachery, infantilisation, disempowerment, labelling and stigmatisation. He also identified io elements of positive interaction (positive person work), including validation, recognition, negotiation and facilitation which, he argued, could draw people with dementia into the social world and meet their psycho-social needs for comfort, attachment, inclusion, identity, occupation and ultimately for love. The last represent person-centred care in practice and are based on the principle that the personhood of individuals should be and can be preserved through an ethic of respect, which is demonstrated by positive interaction in relationships.

Although difficult in practice (Brooker 2004; Dewing 2004), the personcentred approach has been influential in acknowledging the enduring personhoods of people with dementia. It can, however, be critiqued for failing to consider the many ways in which people with dementia continue to express aspects of themselves, even as dementia progresses. In order to address this weakness and to understand better the dynamics between interaction types and the selfhood and wellbeing of people with dementia, this paper will describe and develop Sabat's (200I) selfhood approach and argue for the integration of the two approaches. 


\section{The self in dementia}

In the field of dementia care, the 'Selfs framework' evolved with the work of Sabat and Harré (1992), who argued against the dominant assumption of a loss of self as dementia progresses (see Cohen-Mansfield, Golander and Arnheim 2000; Davis 2004; Fontana and Smith I989). Their approach was extended (Sabat 200I; Sabat and Collins i999) to include three discursive aspects of the self (Selfs I-3), as described below.

Self $I$ is that which expresses first-person pronouns or identifiers ' $I$ ', 'me', 'myself', 'mine' or 'ours'. This aspect of self reflects the fact that each person has a single point of view in the world. By using first-person pronouns, we take responsibility for our actions, locate for others our experiences and feelings, and tell stories about ourselves. Self I can be expressed verbally, for example: 'That's mine' or 'I like that', or through visual expressions which signify identification with oneself, for example, reacting to one's name being called, taking possession of an object or reacting to protect oneself. Sabat (200I) suggested that Self I remains largely intact in people with dementia, even with severe cognitive decline.

Self 2 comprises one's physical, mental or emotional characteristics and attributes, and also one's beliefs and desires about them. Some Self 2 attributes have long histories, for example, past achievements, while others are more recent, for example, increasing frailty. A valued or desired Self 2 attribute can be reclaimed through affirming interaction with others. Positive expressions of Self 2 include articulating awareness of characteristics and attributes: 'I can do that' or remembering achievements from long ago. Positive visual expressions of Self 2 could be admiring oneself in the mirror. Self 2 can also be expressed in negative terms, e.g. 'I can't do that', by reluctance to engage in something, and by becoming upset, frustrated or angry at one's inabilities. Sabat (200I) suggested that Self 2 remains largely intact with cognitive decline, although it is vulnerable when others interpret difficulties caused by dementia as being attributable to the person rather than the condition. Such 'malignant positioning' by others contributes to a loss of self-worth and will be discussed further below.

Self 3 is the publicly presented aspect of ourselves; the roles we take on and the ways in which we behave in social situations. We have many Selfs 3, which we express in different social circumstances; as parent, friend, professional, carer or cared-for person. Each Self 3 requires different ways of behaving and carries with it different expectations. Expressions of Self 3 could include enacting a familiar role, such as a wife or husband, showing regard towards each other, being protective, being gracious or showing agency (Sabat and Collins I999). Self 3 is constructed, 
sustained, nurtured or changed through interaction with others and is more vulnerable to damage than Selfs I and 2. Thus, others' positioning of people with dementia helps to define, strengthen or weaken their social identities (Sabat 2002; Sabat, Napolitano and Fath 2004). Negatively positioning people with dementia because of their physical or cognitive difficulties is to position them in a potentially malignant way (Sabat 2006). This renders people with dementia particularly vulnerable in social situations; as they depend on the affirmation and co-operation of others to coconstruct (Snyder 2006) and support a valued selfhood.

Sabat (200I, 2005) has been pivotal in arguing for the persistence of self, even with serious cognitive decline, and particularly in implicating interactions with others in contributing to damage to selfhood. Selfhood should, however, be considered as the complex interplay between a number of social and biographical factors, including inter-personal relationships, the social context, opportunities for and abilities to communicate aspects of self, and individual coping styles and strategies (Surr 2004). While these accounts of the management and maintenance of the self rely on the communication abilities of people with dementia, their findings are less easily applied to people with increasing communication difficulties. It is now accepted that communication with people with advanced dementia is possible (Killick and Allan 200I), but as care-givers often fail to attend properly, to hear or to recognise attempts to communicate (Innes and Capstick 200I), their wish and capacities to communicate may be missed. Li and Orleans (2002) found that through close observation they were able to discern the individuality of participants with limited verbal communication. From a study of non-verbal presentations of self, Hubbard et al. (2002) noted that people with advanced dementia, acting in the context of shared meaning, used body posture to present particular personae, for example as an active listener. The many incidents of non-verbal communication they identified suggest that people with advanced dementia will work to remain part of the communicative world and to preserve their sense of self.

\section{The research setting}

The study was carried out during $2005^{-6}$ in three 20-bedded long-term psycho-geriatric wards of a hospital in the United Kingdom. Ward I was a mixed-gender unit for those awaiting long-term placement, although some patients had been there for over two years. Wards 2 and 3 cared for women and men, respectively, many of whom were identified as having 'challenging' or inappropriate sexual behaviour. Most of the patients had 
some form of dementia and all I4 participants in this study had a clinical diagnosis of a dementia; with Mini-Mental State Examination $\left(\mathrm{MMSE}^{1}\right)$ scores ranging from 7/30 to 2I/30. All the wards were locked with most patients having little or no access to fresh air. Each of the wards had a similar layout; having a long, narrow corridor that gave access to sitting rooms, the dining room, the four-bed bedrooms, bathrooms, staff office and store rooms. The participants sat in the sitting room or on armchairs lined along the corridor, or walked up and down throughout the ward, with some frequently trying the front door in vain attempts to leave. Although uncharacteristic of dementia settings in the United Kingdom, regional variations mean that such settings continue to provide continuing care for those people with dementia who have complex needs.

In all three wards, the charge nurses were seldom seen, as they had duties elsewhere in the hospital. This meant that the ward staff received few consistent messages on what constituted good care. On each shift, a trained nurse was accompanied by up to five care assistants and up to two student nurses on placement. Throughout my six months of fieldwork, there were no in-service training sessions for ward staff. One care assistant remarked, when asked about her training needs, 'I've been here for I7 years, I know all there is about dementia'. This reflects the generally perceived lack of need for training in dementia care in this setting.

\section{Methodology and methods}

This multi-method observational study was carried out over six months. ${ }^{2}$ The inclusion criteria for the participants were that they were long-term patients in the hospital, had a diagnosis of a dementia and took part in weekly creative sessions facilitated by the occupational therapists (OTs). The principal research methods were extensive non-participant observation and recording of field notes, Dementia Care Mapping ${ }^{3}$ (Bradford Dementia Group i997), and video-recording of the participants' engagement with the OT staff during the weekly creative sessions. The rationale for the study was our anticipation that the interactions between the occupational therapists and the participants with dementia would be qualitatively different from those between ward staff and the participants, which would enable an examination of how different interaction types influence well- or ill-being and expressions of self.

\section{Dementia Care Mapping}

Dementia Care Mapping (DCM) claims to be a powerful observational tool. It evaluates the quality of the care that people with dementia receive 
in formal care settings such as hospitals, day centres and residential and nursing homes. Its grounding philosophy is person-centredness and its aim is to measure how person-centred principles are applied in care environments and experienced by those with dementia (Kuhn, Ortigara and Kasayka 2000). ${ }^{4}$ While originally designed as a practice audit tool for improving the quality of care in care settings, DCM is increasingly being used in research which has the final aim of improving the quality of care (Bredin and Kitwood I995; Brooker et al. 1998; Innes and Surr 200I). As an approach that puts person-centredness at its core, however, DCM codes do not provide the means for clearly hearing the voice of people with dementia (Capstick 2003) - specifically for documenting the expressions of self identified in this study. Even though the revised eighth version of the mapping procedure (DCM8) (Brooker and Surr 2005) does incorporate aspects of self-expression in the coding, these are implicit and require interpretation, rather than being explicitly sought during the mapping. Despite its limitations, however, no one has yet developed a better method for evaluating dementia care (Innes, Capstick and Surr 2000). DCM has been shown to be a valid tool (Fossey, Lee and Ballard 2002) and, as its operational rules demand a consistent approach to data collection, this avoids the bias that affects field notes. As such, it remains the method of choice for those concerned with evaluating and improving the lives of people with dementia.

\section{Data collection}

Fourteen participants gave open-ended consent (Dewing 2002) on a daily basis, and signed consent was obtained from all the ward and OT staff. Extensive field notes from non-participant observation were taken for six to eight hours each day over four weeks in each ward. A six-hour DCM was also carried out on every creative session day, along with field notes and video-recording creative sessions. When the OT staff came to set the tables with paints and paper for the creative session, I followed whichever participants agreed to join them and, with their consent, would set up the video-camera to record the session. During this time, other participants were not mapped until rejoined after the session. All participants were then mapped for the remainder of the six hours. Altogether, I7 six-hour DCMs and I7 video-recordings of varying lengths were carried out over six months. Table I lists the stages of data collection and Table 2 the frequency of participation in each stage. As Table 2 shows, in Ward I, three participants were mapped, including one who took part in creative sessions. In Wards 2 and 3 , five participants were mapped, of whom three took part in creative sessions. In Ward 3 , because of the mobility of 
T A в L E I. The data collection stages

\begin{tabular}{|c|c|c|c|c|}
\hline Stage & Purpose & Time scale & Methods & Data source \\
\hline I & $\begin{array}{l}\text { To become familiar with } \\
\text { participants and vice versa. } \\
\text { To observe and document } \\
\text { their social worlds. }\end{array}$ & $\begin{array}{l}\text { 6-8 hours a day } \\
\text { for } 2 \text { weeks in } \\
\text { each ward }\end{array}$ & $\begin{array}{l}\text { Non-participant } \\
\text { observation }\end{array}$ & Field notes \\
\hline 2 & $\begin{array}{l}\text { To document and classify the } \\
\text { interactions experienced by } \\
\text { people with dementia in } \\
\text { wards and during creative } \\
\text { sessions, and their responses } \\
\text { to interactions in terms } \\
\text { of well-/ill-being and } \\
\text { self-expression. } \\
\text { Continued observation and } \\
\text { documentation. }\end{array}$ & $\begin{array}{l}2-3 \text { days a week } \\
\text { for } 6-7 \text { weeks } \\
\text { in each ward }\end{array}$ & $\begin{array}{l}\text { Six-hour DCMs } \\
\text { on creative } \\
\text { session days and } \\
\text { video-recording } \\
\text { creative sessions } \\
\text { Non-participant } \\
\text { observation }\end{array}$ & $\begin{array}{l}\text { DCM data } \\
\text { Field notes and } \\
\text { DCM data } \\
\text { derived from } \\
\text { video-recordings } \\
\text { Field notes }\end{array}$ \\
\hline 3 & $\begin{array}{l}\text { To seek participants' opinions } \\
\text { about the creative sessions. }\end{array}$ & $\begin{array}{l}\text { I hour for each } \\
\text { participant }\end{array}$ & $\begin{array}{l}\text { Focused } \\
\text { conversations } \\
\text { with participants }\end{array}$ & $\begin{array}{l}\text { Transcripts } \\
\text { Field notes }\end{array}$ \\
\hline
\end{tabular}

Note: DGM: Dementia Care Mapping (for details, see text).

T A B L E 2. Methods of data collection and frequency of participation

\begin{tabular}{|c|c|c|c|c|}
\hline $\begin{array}{l}\text { Setting and } \\
\text { participant }\end{array}$ & $\begin{array}{l}\text { Six-hour } \\
\text { DCM }\end{array}$ & $\begin{array}{l}\text { Creative sessions } \\
\text { attended }\end{array}$ & Video-recordings & $\begin{array}{c}\text { Focused } \\
\text { conversations }\end{array}$ \\
\hline & \multicolumn{4}{|c|}{ Frequencies } \\
\hline Ward I: & & & & \\
\hline Edward & 5 & 2 & 2 & o \\
\hline Florence & 2 & I (US) & I $(\mathrm{US})^{1}$ & o \\
\hline Nora & 4 & o & o & o \\
\hline \multicolumn{5}{|l|}{ Ward 2: } \\
\hline Mary & 6 & 4 & 4 & o \\
\hline Hannah & 6 & 5 & 4 & o \\
\hline Isabel & 6 & 4 & 4 & I \\
\hline Brenda & 6 & o & o & o \\
\hline Kate & 6 & o & o & o \\
\hline \multicolumn{5}{|l|}{ Ward 3 : } \\
\hline Bill & 4 & 4 & 4 & I \\
\hline William & 4 & 3 & 3 & I \\
\hline John & 6 & $5(\mathrm{I} \mathrm{VB})$ & $5(\mathrm{I} \mathrm{VB})$ & o \\
\hline Charlie & 4 & o & o & o \\
\hline Paul & 2 & o & o & o \\
\hline
\end{tabular}

Notes: Pseudonyms are used throughout. DGM: Dementia Care Mapping. US: unsuccessful. VB: very brief. I. Unsuccessful recording of Florence's participation at the creative session through her decision to leave the table five minutes after it began.

participants and because several non-participants frequently sought my company, it was not possible to map accurately all five participants at once. In order to make accurate maps while attempting to meet the social 
and attachment needs of other patients, it was decided to map these participants in two groups.

\section{Analysis}

To ensure consistency in the analysis, all the data were examined to determine the participants' responses to interaction types in terms of their well- or ill-being and their expressions of self. All the field notes and the data from each map were initially open-coded to identify broad themes. Then, following DCM's operational rules (Bradford Dementia Group 1997), they were coded into negative and positive interaction types. From each DCM, individual and group well- or ill-being (WIB) values were calculated and individual and group profiles developed. These provided descriptive statistics on participants' well- or ill-being levels during each map. The data were managed using qualitative data-management software (NVivo7). As a lone mapper, it was important to consider the reliability of my coding: the degree to which my choice of coding adhered to DGM operational rules. To ensure reliability, detailed notes were taken to accompany the DCM data to justify the coding decisions, and I regularly sought advice from a DCM trainer and changed codings in the light of such advice.

After each creative session, the video-footage was downloaded from the digital camera on to a laptop and viewed and coded for different elements of interaction. The participants' wellbeing or illbeing (WIB) values were calculated following DCM rules. These data were inserted into relevant timeslots in the DCM spreadsheets. As well as their overall WIB values, the participants' individual and average WIB values were calculated before, during and after the creative sessions. From the DCM, the videofootage and field notes, verbal and visual expressions of Selfs I-3 were identified, coded and managed (following Sabat 200I, 2002, 2005). Taking a symbolic interactionist stance, I took 'the role of the other' (Mead I934) to imagine and define situations as though I were a participant. When coding for Selfs I-3, the field notes were used to remember, re-experience and empathically understand what aspect of their self a participant might have been expressing. I tried to re-experience the context during which the self was expressed, tried to re-experience the emotional content of expression, and tried to remember bodily expression, particularly in identifying visual expressions of the self.

By continuously and critically revisiting and refining the codings, the associations between the interactions, well- or ill-being and the selfexpression were developed. Re-examining and cross-checking the data 
from each method with those from other methods ensured that these findings were valid and consistent. Finally, in response to the realisation that the quality of the participants' self-expression and their levels of wellor ill-being were contingent on the types of interaction that they experienced, the data were re-examined and recoded to develop the emergent concepts of recognised self and supported self, along with their counterparts: unrecognised self and unsupported self. This key development of Sabat's work is the focus of the remainder of this paper.

\section{Key findings}

The analysis of the data made apparent that the participants' interactions with the ward staff were qualitatively different from those with the occupational therapists. The ward staff did engage in some positive interactions, but most often these were brief, being time and task-oriented and minimal: this finding is not new (see Armstrong-Esther, Browne and McAfee 1994; Perrin 1997; Innes and Surr 200I). Many interactions had little potential to raise the participant's wellbeing, and some were damaging or abusive and caused ill-being. All elements of malignant social psychology were noted of varying levels of severity. These findings suggest that the ward staff did not generally work in a person-centred way, as illustrated in this typical field-note extract:

In Ward 3, there is little in the way of empowering, negotiated or respectful interaction. Most of what I see is functional and cursory. I see the nurse in charge restraining a man by placing his hands firmly on the arms of the man, in order to break his will, while the man shouts and tries to struggle free. I see care assistants moving armchairs with men in them without asking or warning. I see them taking men by the hand and pulling them to the toilet.

In contrast to the social bleakness of the wards, during the creative sessions the interactions with OTs were predominantly positive, and all elements of positive person-work were noted. Those who took part in creative sessions had consistently higher average wellbeing values than those who did not participate (Table 3). With sustained supportive interactions from the OT staff, many participants expressed their self with unexpected proficiency: their fragile expression of self could become a robust expression, a past Self 2 was reclaimed and a desired Self 3 co-constructed. Here, in an abridgement of a field note, is how Hannah had qualitatively different experiences in the ward and during the creative sessions, with marked differences in her wellbeing:

Hannah, in the sitting room, looks around her, wriggles and whimpers, 'I don't know, I don't know'. No one notices although there is a care assistant in the 
T А в L E 3. Average well- or ill-being scores of the participants

\begin{tabular}{|c|c|c|c|c|c|c|c|c|c|}
\hline & 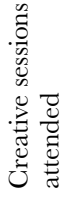 & 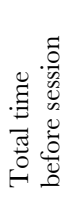 & 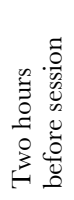 & 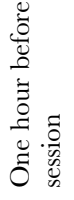 & 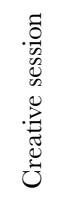 & 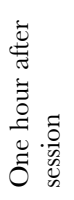 & 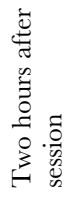 & 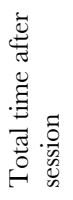 & 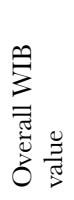 \\
\hline & \multicolumn{9}{|c|}{ Well-or ill-being scores } \\
\hline \multicolumn{10}{|l|}{ Ward I: } \\
\hline Edward & 2 & +0.8 & +0.8 & +0.9 & + I.O & $+\mathrm{I} .5$ & + I.I & $+\mathrm{I} . \mathrm{I}$ & + I.O \\
\hline Florence & o & & & & & & & & +0.8 \\
\hline Nora & o & & & & & & & & +0.8 \\
\hline \multicolumn{10}{|l|}{ Ward 2: } \\
\hline Mary & 4 & + I.I & + I.I & $+\mathrm{I} . \mathrm{I}$ & +2.5 & + I. 6 & + I.I & $+\mathrm{I} \cdot 3$ & $+\mathrm{I} \cdot 3$ \\
\hline Hannah & 5 & +0.4 & +0.4 & +0.6 & +2.5 & +0.9 & +0.9 & +0.9 & +0.9 \\
\hline Isabel & 4 & + I.I & +0.9 & +0.9 & +2.4 & $+\mathrm{I} \cdot 4$ & + I.O & $+\mathrm{I} \cdot 3$ & $+\mathrm{I} \cdot 3$ \\
\hline Brenda & o & & & & & & & & +0.8 \\
\hline Kate & o & & & & & & & & +0.6 \\
\hline \multicolumn{10}{|l|}{ Ward $3:$} \\
\hline Bill & 4 & + I.O & +0.8 & + I.o & +2.6 & $+\mathrm{I} .2$ & $+\mathrm{r} .8$ & + I.6 & $+\mathrm{I} .5$ \\
\hline William & 3 & +0.9 & +0.8 & $+\mathrm{I} . \mathrm{O}$ & $+\mathrm{I} .5$ & $+\mathrm{I} .4$ & $+\mathrm{I} .2$ & $+\mathrm{I} \cdot 3$ & $+\mathrm{I} \cdot 3$ \\
\hline John & 5 & +0.8 & +0.7 & +0.9 & $+\mathrm{I} .9$ & $+\mathrm{I} .4$ & +0.9 & $+\mathrm{I} . \mathrm{I}$ & $+\mathrm{I} \cdot 3$ \\
\hline Charlie & o & & & & & & & & +0.4 \\
\hline Paul & o & & & & & & & & +0.3 \\
\hline
\end{tabular}

Notes: WIB: well- or ill-being. The mean WIB scores were calculated from data collected at I7 six-hour Dementia Care Mappings. Each person was also mapped during their time at the creative session, ranging from 30 minutes to one hour. The total time before and after each creative session was approximately two-and-a-half hours for each participant.

room. Hannah whimpers in distress over and over, 'I don't know where to go'. There are now two other care assistants in the room, feeding other patients but neither of them even glance at her. Shortly afterwards, Eddie (OT) comes in and speaks gently with her. He asks her if she would like to come and do some art and Hannah agrees. She is so frail, but she still manages to paint, and she smiles and gesticulates, although with less vigour than usual. When she paints she does so with confident strokes and with lots of support and encouragement from Eddie. Occasionally it appears that she becomes worried, but Eddie steps in to reassure her. At one stage, when she is painting, her eyebrows move up and down, as I have seen before. She relaxes, then engages with Eddie and she smiles.

As shown in Table 3, in most cases following the creative sessions, WIB values slowly deteriorated. This might be because the staff did not recognise the participants' distress and so were unable, to support its amelioration. It was by interrogating the data (including the reproduced extracts) in the context of a theoretical integration of Kitwood's (I997) and Sabat's (200I) work that the crucial link between recognising and supporting self (or not) and the types of staff interaction was made. These 
concepts will now be discussed in more detail and their implications for practice developed.

\section{Recognised self}

The concept recognised self captures instances in which staff acknowledged or identified with aspects of a participant's self. While being similar to Kitwood's (I997) idea of recognition in positive person work (in which people are acknowledged by name or through facial recognition and in which their uniqueness is affirmed), recognised self extends this concept by recognising Selfs $\mathrm{I}^{-} 3$ in interaction - as opposed to simply recognising the person. The OT staff recognised all aspects of the self, whereas the ward staff generally recognised Self I, but less often Selfs 2 and 3. On one particularly warm occasion, a care assistant recognised Hannah's valued Self 2 attributes - her love of colours and her painting ability - and also recognised Hannah's Self 3 - her artist persona:

'You like colours, Hannah'. Hannah nods and smiles. 'Hannah's a great painter', she says, and Hannah nods and smiles. The care assistant tells me that Hannah has drawn some great pictures of the staff. Hannah continues to nod and smile and gesticulate with her hands.

Here is clear evidence of increasing wellbeing with the care assistant's recognition of Hannah's creative ability (Self 2) and her proficiency as an artist (Self 3). While this required some knowledge of Hannah's biography, this level of recognition could have been achieved through careful observation of Hannah's behaviour in the wards and creative sessions. The key lesson here is that recognition of the self of the person with dementia has the potential to foster meaningful interaction, with subsequent increases in wellbeing.

\section{Unrecognised self}

This concept captures the instances during which the staff did not recognise a participant's self as evinced by abusive behaviours, invalidation, and withholding or a failure to acknowledge a participant's subjective experiences. There were no instances when an OT failed to recognise a participant's self during their interactions, but many of my field notes indicate that the ward staff did not fully recognise their patients' selfhoods. For example, from Ward 2:

The staff are in the big sitting room are chatting together. Someone is rattling persistently on the front door, another is calling loudly and someone else is sobbing. 
This incident demonstrates a generalised lack of awareness by staff of their patients as people with social, physical, occupational, relational or emotional needs, thus their interactions with them were limited at best and abusive at worst. There were also occasions when the staff did not seem to recognise individual aspects of a participant's self, with consequences both for how they interacted with that person and her or his subsequent wellbeing, as shown in the following field note extract. The elements of malignant social psychology are noted in parentheses.

The staff are gathering patients to go for a stroll. I have noticed that $\mathrm{B}$, the care assistant, seldom smiles and that even when talking normally, her tone sounds accusatory. She asks Edward if he would like to go for a walk - 'Aye' he says, but by the time she returns with his jacket, he seems to have forgotten. She shakes the jacket in front of him - 'Come on' (outpacing, infantilisation). 'Eh?' says Edward. 'You're going for a walk', she says loudly. 'Eh?' says Edward. 'YOU'RE GOING FOR A WALK' she shouts, shaking the jacket at him (outpacing, infantilisation, intimidation). 'Oh aye', and he allows his jacket to be put on (disempowerment). Shortly afterwards, while waiting for everyone else to get ready, B approaches him with a tissue to clean his face. No warning (disruption, imposition, infantilisation, objectification). Edward jumps and hits out defensively with his hands. B talks loudly and crossly: 'You've got food on your face, you need to get it cleaned', and she tries again (intimidation, invalidation, imposition, objectification). Edward becomes angry. 'No, no', he says as he tries to hit out at her. B shouts at him: 'do it yourself then', and throws the tissue at him (intimidation), before walking away.

These elements of malignant social psychology conjoin with the nonrecognition of Edward's Selfs 2 and 3 and only superficial recognition of Self $\mathrm{I}$. Each aspect of self in this exchange will be examined in turn. While B recognised Self I, by referencing Edward as 'you', she was unable to engage with him in a way he could understand. The time lapse meant that the jacket held no meaning for him and, despite her repetitions, he was unable to make sense of the encounter. Had B reminded him that he had said he would like to go for a walk and that she had his jacket for him to put on, he might have understood the situation without the need for her to shout at him. The recognition of Self I required understanding of the reasons for certain behaviours. When Edward reacted defensively to B's approach to him with the tissue, he was expressing Self I - a normal response to a perceived threat. Had she understood this, she might have modified her approach and requested permission to clean his face, thus minimising the possibility of distress.

A better approach would have been to alert Edward to his dirty face and offer him a warm, damp, cloth to clean it. This would have recognised (and supported) his Self 2, his remaining ability to care for himself. With an understanding of Edward's remaining ability, it is likely that her interactions with him would have been quite different, with very different 
outcomes for both parties. Furthermore, Edward was a fit, active man and could have put the jacket on himself, but B did not recognise this intact aspect of his self and put the jacket on for him, thus denying him the chance to carry out ritual, meaningful behaviour.

In her interactions with Edward, B infantilised him: she treated him as a parent might treat a very young child. Because she did not fully recognise his Self 3 or adult persona, she did not treat him with the dignity an adult normally expects. By imposing her will on him, she denied him the choice that an adult would expect; and by shouting at him, she denied him respect. Not recognising Self 3 in the interaction produced the elements of malignant social psychology noted above, and resulted in the consequent sequence of negative responses and reactions. These examples, by extending on the work of Sabat (200I) in the context of a person-centred approach to care, clearly illustrate the potential for limited and sometimes harmful staff interactions when a cared-for person's self is not recognised.

\section{Supported self}

This supported self concept captures the occasions when staff interacted in ways that affirmed or bolstered aspects of a participant's self. On one occasion, a staff-nurse supported Edward's Self 3 -his persona as a working man. He had spent the morning in restless isolation and was tense and terse. The field note continues:

She calls over to Edward to come for lunch. 'No, no', he replies. 'Oh come on, Edward'. 'NO'. Then she asks him to help her push the drugs-trolley up to the dining room. Up he jumps and, making his funny face, he starts to push the trolley towards the dining room. He pushes it all the way up and positions it where the nurse indicates. 'There, there', he says, smiling.

The nurse recognised Edward's Self I (calling him by name), but she also supported his need for occupation by encouraging him to perform a needed task. His mood changed from one of belligerence and noncooperation to one of willingness and wellbeing. By supporting his Self 3 , the nurse not only turned around a situation of potential conflict, but also promoted Edward's sense of worth, achievement and pride.

The impact of interactions which supported a participant's self was most marked during the creative sessions. This was particularly the case with Hannah and Mary, who were often distressed in the ward. The following field-note extract typifies the transformation that occurred in Mary as OT staff supported her when she was painting:

At the start of the creative session Mary's talk is uncertain and questioning: 'What shall I do, darling?' Or self-deprecating: 'My goodness, I could never do 
that!' Mary initially needs a lot of encouragement and seems unsure of what to do, or of how to do it. Karen (OT) guides her hand to the paints, the water and the paper, sometimes holding and guiding her hand while she paints, sometimes painting for her at Mary's direction. But there comes a turning point when Mary starts to colour in the petal of a flower they have drawn, following the shape of the petal. This is her first solo effort and is praised by Karen. Then, with more assurance, Mary draws a green vertical line (the stem of the flower she and Karen have drawn). Mary seems surprised and pleased, and says: 'I got by with it!' Soon the painting is complete and Mary chuckles with pleasure.

In this extract, Karen supports Mary's Self 2 - her dexterity with a paint brush. While initially unsure about her abilities, with encouragement, turn-taking and guidance, Mary's confidence begins to emerge and she takes control over the session, even directing Karen in painting. As the session progresses, Mary reclaims a past Self 2 attribute and expresses surprise and pleasure both in the process and with the product. These examples show that once a participant's self was recognised, a staff carer could then work to facilitate its expression. This is akin to the idea of 'scaffolding' in child development (Wood, Brunner and Ross i976), by which the parent or carer provides the level of support needed in order for the child to carry out a task, reduces the support as the child gains proficiency. The presented evidence provides further evidence of the value of the selfhood approach, as developed here, to facilitate person-centred dementia care.

\section{Unsupported self}

This unsupported self concept captures the occasions when a participant tried to express aspects of her or his self, but the staff did not act on the selfexpression; that is, the interaction required to support self-expression was either absent or insufficient. In the wards, there were many occasions when the staff did not support a participant's self (as with the many instances of unrecognised self-interactions). While the ward staff frequently recognised Self I, they often did not go further to support the participants' selves. This is illustrated by one example from the field notes:

Hannah has slipped into ill-being ... she has her head in her hands; is bent over and wriggling. She remains in ill-being for over io minutes. A staff nurse passes by and notices her bent over position. 'Are you alright in there, Hannah?' she asks. Hannah immediately lifts her head up and looks around, a smile on her face, but the nurse is gone.

In this extract, the nurse recognised Self $\mathrm{I}$, in that she called Hannah by name, but by not waiting for a response, she failed to support Hannah's 
expression of Self I, thus leaving the interaction incomplete. Further, because it seemed that the ward staff seldom recognised Self 3 (the individual persona), they often could not interact in ways which supported this aspect of a participant's selfhood. For example, when Nora tried to enact Self 3 (a domestic persona), the staff did not recognise or support her efforts, which resulted in ill-being:

Nora is walking the corridor, unsettled and out of sorts. She starts looking for the key to get out in order to 'make my man's tea'. She is becoming agitated, as her repeated attempts to find someone with a key are unsuccessful. Nora asks the staff nurse for the key, he shows her his one, her face lights up but he puts it back in his pocket. Her face falls and she looks puzzled. He talks conspiratorially in her ear, 'don't tell anyone, I'll let you out later'. And away he goes, leaving Nora standing.

In this extract, there is little recognition of the importance for Nora of her domestic persona and the accompanying roles - in this instance, going home to make her husband's tea. Had he tried to reminisce with her about her domestic life or help her accomplish a domestic task, such as laying the table, he might have alleviated her anxiety and her desire to go home. Instead, his actions, driven by non-recognition of the importance for Nora of her domestic persona, increased her distress. As evinced throughout this paper, a crucial feature of the impact of the staff's interactions was whether or not he or she recognised or supported the participant's self. The concluding sections of the paper consider the implications of these findings.

\section{A person-centred/selfhood approach to dementia care}

A person-centred approach requires sustained critical self-reflection of those who try to work within its ethos. It also requires energy, motivation, sufficient resources, staff support and, for those who are not yet aware of its principles, training and reinforcement. In reality, the approach is not easy to sustain in the daily care of people with dementia who display a wide range of needs, emotions and responses. The poor status of care work, which lacks glamour and professional prestige, and care workers' lack of political influence (Innes 2002), probably impedes a move towards a more person-centred approach. Brooker (2004) and Dewing (2004) contend that, without changes in policy, practice, staff selection or national policy frameworks, services will not assimilate person-centred principles. Packer (2000) called for the same values of person-centredness to be applied to care workers in order that their own personhoods are nurtured and their practice enhanced, and reflected that with inadequate 
staff-training, support and resources, this will be difficult to achieve. Despite these barriers to achieving person-centredness in dementia care, I argue that we should still strive towards person-centred practice.

The data presented in this paper indicate that recognising and supporting a person with dementia's sense of self (or not) can result in either positive (or negative) elements of interaction with consequent implications for the wellbeing (or ill-being) of the cared-for person. By way of developing the argument for using the concepts of recognised self and supported self to inform a person-centred approach, I now consider the transactional repercussions of recognising and supporting Self 2 (or not) in interactions. This argument can be applied to all aspects of the self.

As discussed, in their interactions with the participants during the creative sessions, the occupational therapists were most skilled at recognising participants' Self 2; their past, present and potential abilities. For example, when they invited someone to the creative sessions, they recognised her or his potential creative abilities. They were also skilled at supporting expressions of Self 2. For example, when OT staff encouraged Hannah to paint, she blossomed as she again used her painting skills (expressing her past and present Self 2) and as she co-constructed with them her artist persona (her Self 3 ). Because the OT staff recognised and supported the self, they interacted in ways which sustained it - their interactions were both facilitative and celebratory. This raised participants' wellbeing, as seen in increased wellbeing, the emergence of humour, and increased selfconfidence. It also elicited expressions of pleasure and pride, which in turn prompted reciprocal positive interactions from OT staff. This way of viewing and interacting with people with dementia has the potential to fuel a transactional flow of positive interactions.

The ward staff less often recognised and seldom supported Self 2. For example, as described, they disempowered participants by pulling them along by their hands instead of allowing them to walk at their own paces; they often did tasks which the participants would have been able to do themselves, and even though they often noticed when participants expressed a need, they did not offer supportive care. This caused much distress for the participants, and resulted in lower wellbeing scores. It would then follow that as most ward-staff did not seem to recognise or support a participant's self, they could not interact in ways which sustained it, and thus they interacted in limited and sometimes damaging ways, which often resulted in the participant's isolation and ill-being, in turn prompting further limited interactions from the ward staff. This way of viewing and interacting with people with dementia tends to fuel a transactional flow of negative interactions. Without being judgemental of the ward staff, this points to how one can become locked into negative ways of interacting, 
with negative implications for all parties within the interaction. Using this development of Sabat's (200I) work to facilitate a person-centred approach offers an innovative way to improve what is already a difficult field of practice. As with any new approach to care, it would require training and mentoring to bring about a change in thinking and practice, and requires evaluation to assess its effectiveness.

\section{Implications and conclusions}

This paper has reported a small observational study of care practice that offers rare insights into the social worlds of people with dementia, an often marginalised and forgotten group, many of whom end their lives in the locked wards of institutional settings. By integrating the person-centred and selfhood approaches throughout the data collection and analysis, a deeper understanding of the operational elements of interaction and well-/ill-being were identified, as well as operational elements of the participants' self-expression. This has made evident the transactional nature of interactions in influencing wellbeing and self-expression. With this development of Sabat's (200I) work, it has been shown that while many hospital ward staff recognised Self I in their everyday interactions with participants, they were less able to recognise Selfs 2 and 3 and seldom engaged in support for the self. Many times this resulted in limited or abusive behaviours with consequent participant ill-being. The OT staff, in contrast, generally seemed to recognise and support Selfs $\mathrm{I}^{-3} 3$ in their interactions during creative sessions; indicated by sustained positive elements of interaction which raised the participants' wellbeing.

These findings suggest that the old culture of institutional and regimented care in the wards survives, as described by Kitwood (1997: I36). In this, the patients' physical needs are cared for at the expense of their psycho-social needs, and 'problem behaviours' are sometimes managed by medication or punitive interactions. It seems that little has changed since Armstrong-Esther, Browne and McAfee (I994) reported on the minimal task-oriented interactions between nursing staff and old, frail institutionalised people. In this reported setting, care remained custodial (indicated by the locked wards), there was little emphasis on restorative interactions, and patients spent long stretches of time in isolation (Nolan, Grant and Nolan i995). It is clear that in institutional environments where work is regimented, focused on order, and restricted to the performance of physical tasks, delivering a person-centred approach is extremely difficult without extensive support, mentoring and organisational change. As the incidence of dementia increases globally, placing increasing demands on 
resources, new ways must be found to ensure to support an over-stretched care work-force.

I therefore recommend a shift in focus, from examining elements of the care interaction to looking outwards towards those for whom we care. If practitioners are taught to recognise and support verbal and visual expressions of the self of the person with dementia, this might promote a new way of viewing and engaging with them. It might encourage ward staff to view their patients as purposeful, sentient people and encourage them to recognise and respond to aspects of the patients' selves as they carry out care, which would foster more meaningful interactions and ultimately improve their patient's wellbeing. Further, even the staff who know little about their patients (because they are new to the care setting or because little is known about the patients) will still be able to behave constructively towards them. This paper has developed a deeper understanding of the relationships between a carer's understanding of the selfhood of their patients, its translation into the recognition and support (or not) of during care interactions, and the transactional repercussions for the wellbeing for the patient or resident. The reported analysis offers new directions by which to facilitate a person-centred approach to dementia care.

\section{Acknowledgements}

With grateful thanks to Professor Alison Bowes who patiently commented on the several drafts of this paper, to Professor Sally Wyke and Dr Anthea Innes for comments on earlier drafts, to the anonymous reviewers and to Professor Tony Warnes for his advice throughout. Thank you to the management and staff who gave me access to the research setting, and particularly to the men and women with dementia who welcomed me and who taught me a lesson in humanity.

\section{NOTES}

I MMSE measures cognitive functioning with a possible range from o to 30 (Folstein, Folstein and McHugh I975). A score between io and ig indicates moderate dementia and a score of 9 or less indicates severe dementia. MMSE scores are included only to indicate the diagnosed level of cognitive functioning. The author does not subscribe to a stage theory in considering cognitive functioning, preferring instead to look for potential rather than decline.

2 Ethical approval was granted from the Multi-centre Research Ethics Committee (Scotland), the National Health Service Local Research Ethics Committee and the Research Ethics Committee of the Department of Nursing and Midwifery, University of Stirling. 
3 The author is accredited to carry out DCM, having attended a three-day intensive course. Permission to use DCM in this study was given on the understanding that the researcher verified codings (in conjunction with detailed observational notes) with one of her supervisors who is a DCM trainer.

4 See Innes and Kelly (2007) for the practicalities of carrying out DCM in an institution.

\section{References}

Armstrong-Esther, C. A., Browne, K. D. and McAfee, J. G. I994. Elderly patients: still clean and sitting quietly. Fournal of Advanced Nursing, 1 9, 2, 264-7I.

Bradford Dementia Group 1997. Dementia Care Mapping Manual. Seventh edition, Bradford Dementia Group, University of Bradford, Bradford, UK.

Bredin, K. and Kitwood, T. I995. Decline in quality of life for patients with severe dementia following a ward merger. International fournal of Geriatric Psychiatry, ro, I , 967-73.

Brooker, D. 2004. What is person-centred care in dementia? Reviewes in Clinical Gerontology, I3, 3, 215-22.

Brooker, D., Foster, N., Banner, A., Payne, M. and Jackson, L. I998. The efficacy of Dementia Care Mapping as an audit tool: report of a 3-year British NHS evaluation. Aging and Mental Health, 2, I, 60-70.

Brooker, D. and Surr, C. 2005. Dementia Care Mapping: Principles and Practice. Bradford Dementia Group, Bradford, UK.

Capstick, A. 2003. The theoretical origins of dementia care mapping. In Innes, A. (ed.), Dementia Care Mapping: Applications Across Cultures. Health Professions Press, Baltimore, Maryland, I I-23.

Cohen-Mansfield, J., Golander, H. and Arnheim, G. 2000. Self-identity in older persons suffering from dementia: preliminary results. Social Science and Medicine, 5I, 3, 38I-94.

Davis, D. 2004. Dementia: sociological and philosophical constructions. Social Science and Medicine, 58, 2, 369-78.

Dewing, J. 2002. From ritual to relationship: a person-centred approach to consent in qualitative research with older people who have a dementia. Dementia, I, 2, I57-71.

Dewing, J. 2004. Concerns relating to the application of frameworks to promote personcenteredness in nursing with older people. Fournal of Clinical Nursing, $\mathbf{1 3}$, 3a, 39-44.

Folstein, M., Folstein, S. and McHugh, P. 1975. Mini-mental state exam: a practical method for grading the cognitive states of patients for the clinician. Fournal of Psychiatric Research, 12, 3, 189-98.

Fontana, A. and Smith, R. 1989. Alzheimer's disease victims: the 'unbecoming' of self and the normalization of competence. Sociological Perspectives, 32, I, 35-46.

Fossey, J., Lee, L. and Ballard, C. 2002. Dementia Care Mapping as a research tool for measuring quality of life in care settings: psychometric properties. International fournal of Geriatric Psychiatry, I 7, iा, ro64-70.

Hubbard, G., Cook, A., Tester, S. and Downs, M. 2002. Beyond words: older people with dementia using and interpreting nonverbal behaviour. Fournal of Aging Studies, r6, 2, I $55^{-67 .}$

Innes, A. 2002. The social and political context of formal dementia care provision. Ageing \&? Society, 22, 4, 483-99.

Innes, A. and Capstick, A. 20or. Communication and personhood. In Cantley, C. (ed.), A Handbook of Dementia Care. Open University Press, Buckingham, UK, I35-46.

Innes, A., Capstick, A. and Surr, C. 200o. Mapping out the framework. Fournal of Dementia Care, 7, 2, 20-I. 
Innes, A. and Kelly, F. 2007. Evaluating long stay settings: reflections on the process with particular reference to Dementia Care Mapping. In Innes, A. and McCabe, L. (eds), Evaluation in Dementia Care. Jessica Kingsley Publishers, London, I44-6o.

Innes, A. and Surr, C. 200r. Measuring the well-being of people with dementia living in formal care settings: the use of Dementia Care Mapping. Aging and Mental Health, 5, 3, 258-68.

Judd, S. 2007. Citizenship and dementia: some inconvenient truths. Fournal of Dementia Care, I 5, 3, I9-2I.

Kelly, F. 2007. Well-being and Expression of Self in Dementia: Interactions in Long-term Wards and Creative Sessions. Unpublished thesis, University of Stirling, Stirling, UK.

Killick, J. and Allan, K. 200I. Communication and the Care of People with Dementia. Open University Press, Buckingham, UK.

Kitwood, T. 1997. Dementia Reconsidered: The Person Comes First. Open University Press, Buckingham, UK.

Kitwood, T. and Bredin, K. I992. Towards a theory of dementia care: personhood and well-being. Ageing \& Society, I 2, 3, 269-87.

Knapp, M., Comas-Herrera, A., Somani, A. and Banerjee, S. 2007. Dementia: International Comparisons. National Audit Office, London.

Knapp, M. and Prince, M. 2007. Dementia UK: Summary of Key Findings. Alzheimer's Society, London.

Kuhn, D., Ortigara, A. and Kasayka, R. 200o. Dementia Care Mapping: an innovative tool to measure person-centred care. Alzheimer's Care Quarterly, I, 3, 7-15.

Li, R. and Orleans, M. 2002. Personhood in a world of forgetfulness: an ethnography of the self-process among Alzheimer's patients. Fournal of Aging and Identity, 7, 4, 227-44.

Mead, G. H. I934. Mind, Self and Society. Chicago University Press, Chicago.

National Audit Office 2007. Improving Services and Support for People with Dementia. Stationery Office, London.

Nolan, M., Grant, G. and Nolan, J. 1995. Busy doing nothing: activity and interaction levels amongst differing populations of elderly patients. Fournal of Advanced Nursing, 22, 3, 528-38.

Packer, T. 2000. Does person-centred care exist? Fournal of Dementia Care, I o, 3, I9-2I.

Perrin, T. 1997. Occupational need in severe dementia: a descriptive study. Fournal of Advanced Nursing, 25, 5, 934-4I.

Sabat, S. 2001. The Experience of Alzheimer's Disease: Life Through a Tangled Veil. Blackwell, Oxford.

Sabat, S. 2002. Surviving manifestations of selfhood in Alzheimer's disease. Dementia, I, I, $25-36$.

Sabat, S. 2005. Capacity for decision-making in Alzheimer's disease: selfhood, positioning and semiotic people. Australian and New Zealand Journal of Psychiatry, 39, I / I2, I030-5.

Sabat, S. 2006. Mind, meaning and personhood in dementia: the effects of positioning. In Hughes, J., Louw, S. and Sabat, S. (eds), Dementia: Mind, Meaning and the Person. Oxford University Press, Oxford, 287-302.

Sabat, S. and Collins, M. I999. Intact social, cognitive ability and selfhood: a case study of Alzheimer's disease. American fournal of Alzheimer's Disease, I 4, I, I I-9.

Sabat, S. and Harré, R. 1992. The construction and deconstruction of self in Alzheimer's disease. Ageing $E^{2}$ Society, I 2, 4, 443-6r.

Sabat, S., Napolitano, L. and Fath, H. 2004. Barriers to the construction of a valued social identity: a case study of Alzheimer's disease. American Fournal of Alzheimer's Disease and Other Dementias, 19, 3, I77-85.

Snyder, L. 2006. Personhood and interpersonal communication in dementia. In Hughes, J., Louw, S. and Sabat, S. (eds), Dementia: Mind, Meaning and the Person. Oxford University Press, Oxford, 259-76. 


\section{I24 Fiona Kelly}

Surr, C. 2004. Self in Dementia. Unpublished PhD thesis, Bradford Dementia Centre, University of Bradford, Bradford, UK.

Sutherland, S. 2008. Independent Review of Free Personal and Nursing Care in Scotland. Scottish Government, Edinburgh.

Wood, D., Bruner, J. and Ross, G. 1976 . The role of tutoring in problem-solving. Fournal of Child Psychology and Psychiatry, I 7, 2, 89-100.

Accepted 3 March 2009; first published online I4 August 2009

Address for correspondence:

Fiona Kelly, Dementia Services Development Centre, University of Stirling, Stirling FK9 4LA, UK.

E-mail: fiona.kelly@stir.ac.uk 